\title{
Crack Healing of High Temperature Hydrogen Attack Corrosion by Heat Treatment
}

\author{
Azzura Ismail, Azlizul Aizat Razali, Asliaty Atim, Muhammad Amin Ali, Hariti Hasan
}

\begin{abstract}
Crack healing demonstrate as a ability of metal to repair physical damage by restructuring the carbon microstructure. High-Temperature Hydrogen Attack (HTHA) destruction happens when carbon steel equipment is exposed to hydrogen partial pressure at high temperatures. This will result in damage that severely degrades the mechanical properties of carbon steel. HTHA always happen at high-stress area in carbon steel such as a post-weld-heat-treated weldment and bending area in the form of the fissure exerted by methane gas inside the equipment. As more fissures are formed, it leads to form micro cracks and weaken the steel to cause a rupture. HTHA is difficult and challenging to inspect. In this research, the HTHA locations were identified by magnetic particle inspection (MPI) and heat treatment was performed by heating to annealing temperature and slowly cooled in the furnace. The early stages of attack with fissures or even small cracks detected are difficult to detect. When significant cracking detected, the particular point is already at higher possibilities of equipment to fail. Previous research has elucidated that there is a possibility of HTHA crack to reduce if undergoes for heat treatment. Heat treatment implies carbon diffuse into the matrix and hydrogen atoms escape. Therefore, diffusion plays an important part in the healing of HTHA crack as it plays a key role in the HTHA process. In this study, the specimen is 4-inch $(10.16 \mathrm{~cm})$ elbow pipe of the pipeline between distillation column and heat exchanger with a wall thickness of 1-inch $(2.54$ $\mathrm{cm}$ ) had failed due to HTHA from pipelines which have been operating for 10 years. The failure occurs during operation on the pipelines between distillation column and heat exchanger. The crack length has reduced once the failed part was reheated to the annealing temperature of $850^{\circ} \mathrm{C}$ and slowly cooled in the furnace. The heat treatment by annealing also can be an alternative for altering the structure of the material in order to achieve desired properties and prepare the situation for further decision making by the process operation responsibilities. The conclusion for this research is to identify HTHA locations and restructure the microstructure of affected carbon steel by heat treatment. Results revealed that cracks length had reduced 3 to $10 \%$ by heating the failed pipe to annealing temperature and then slowly cooled for
\end{abstract}

Revised Manuscript Received on April 02, 2020.

* Correspondence Author

Azzura Ismail*, Department of Manufacturing Engineering, Faculty of Mechanical and Manufacturing Engineering, Universiti Tun Hussein Onn Malaysia, Johor, Malaysia. Email: azzura@uthm.edu.my

Azlizul Aizat Razali, Faculty of Mechanical and Manufacturing Engineering, Universiti Tun Hussein Onn Malaysia, Johor, Malaysia. Email: azlizul@mte.com.my

Asliaty Atim, Department of English Language and Linguistics, Centre for Language Studies, Universiti Tun Hussein Onn Malaysia, Johor, Malaysia.Email: asliaty@uthm.edu.my

Muhammad Amin Ali, Faculty of Mechanical and Manufacturing Engineering, Universiti Tun Hussein Onn Malaysia, Johor, Malaysia. Email: amin_twilight596@yahoo.com

(C) The Authors. Published by Blue Eyes Intelligence Engineering and Sciences Publication (BEIESP). This is an open access article under the CC BY-NC-ND license (http://creativecommons.org/licenses/by-nc-nd/4.0/) microstructure recover. However, the hardness had reduced and further research should be extended to overcome this problem.

Keywords : Carbon steel, annealing, hydrogen attack, failure analysis

\section{INTRODUCTION}

High temperature hydrogen attack (HTHA) is form of corrosion attack due to high temperature and hydrogen partial pressure. This attack of steels at high temperature is caused by hydrogen diffusing into the steel and react with carbides (of the steel by decarburization) to form methane gas $\left(\mathrm{CH}_{4}\right)$ which trapped in the steel. The trapped gaseous may form methane bubbles at grain boundaries and due to decarburization process, the steel reduces its strength and toughness especially at elevated temperature and hydrogen partial pressure leading to a rupture [1-4]. The investigation towards the incident concluded that the construction of refinery involved with high temperature and partial pressure of hydrogen need to be contracted with at least $1.25 \mathrm{wt} \%$ of chromium content [5-6]. However, frequent monitoring can be an alarm before a catastrophic accident happen. Normal practice to overcome HTHA and recommended by American Petroleum Institute (API:RP 941) : Steels for Hydrogen Service at Elevated Temperatures and Pressures in Petroleum Refineries and Petrochemical Plants, the Nelson curve is used to predict the occurrence of HTHA in various materials of construction as a function of temperature and hydrogen partial pressure [7-8]. This Nelson curves are predicted based on past equipment failure incidents and plotted based on self-reported process conditions that are ill-defined and still lack of consistency [9]. Table 1 show the operating parameter for this particular process involved the failed part. This guideline is used by corrosion engineer to decide for material upgrade referring to Nelson Curve [9]. Failure analysis such as MPI is one of nondestructive testing in failure analysis which can be done even during the operational process which involved high temperature [10]. The technique can be considered cheap and less hassle. This research was implemented MPI to identify HTHA locations before proceeds for heat treatment at the respective area to gain back its strength and hardness. Apart from identifying the failed area, heat treatment can be an alternative precaution before upgrading the material selection of affected equipment, by the annealing process.

\section{METHODOLOGY}

\section{A. Material Preparation for MPI}

MPI is one of the non-destructive testing techniques which

Published By:

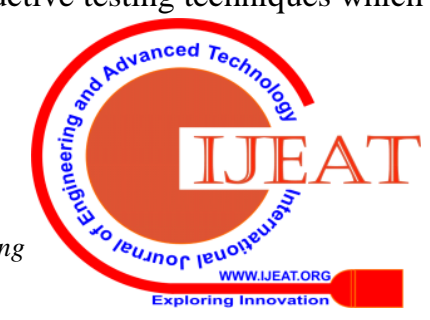

Blue Eyes Intelligence Engineering \& Sciences Publication

(C) Cobvriaht: All riahts reserved. 
can detect surface and shallow sub surfaces flaws in most ferromagnetic materials [11-13].

The procedure for MPI began by cleaning the sample from rust, oil, grease, paint and any contaminations using wire brush and remover. The cleaning process involved using the MPI spray kit that consists of a remover, followed by applying the base and finally the contrast enhancer spray. A clean specimen is shown in Fig 1 (a)-(c) was needed to avoid hindrances which might occur during the MPI procedure. Then, the magnetic field was introduced into the specimen by using a hand-held magnetic yoke (Fig 1d) which induced a magnetic field between two poles and in order to have a proper inspection, every inspection area needed to be rotated to detect horizontal and vertical discontinuities. It was important to ensure that the specimen was being magnetised during MPI while the ferromagnetic medium particles were still airborne and free to be attracted to the leakage fields. The size of indication, intensity and the amount of magnetic field could provide a rough estimation of the discontinuity size. After the HTHA had been discovered through the MPI technique, the failed area was cut using oxy-acetylene torch cutting and wire-cut electrical discharge machining (EDM) cutting, as shown in Fig 2 before proceeding with the heat treatment by annealing.

\begin{tabular}{l|l}
\multicolumn{2}{c}{ Table 1. Operating parameter of pipeline } \\
Parameter & Value \\
\hline Operating temperature & $266^{\circ} \mathrm{C}\left(510.8^{\circ} \mathrm{F}\right)$ \\
Design temperature & $310^{\circ} \mathrm{C}\left(590^{\circ} \mathrm{F}\right)$ \\
Operating pressure & $161 \mathrm{~kg} / \mathrm{cm}^{2}$ \\
Design pressure & $144 \mathrm{~kg} / \mathrm{cm}^{2}$ \\
Service medium & Waxy distillate \\
\hline
\end{tabular}

(a)

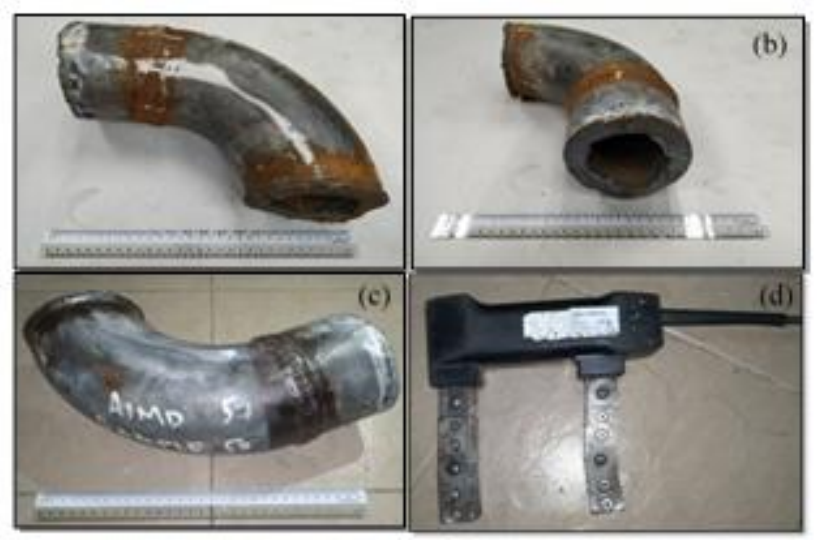

Fig 1. Failed pipe preparation for MPI

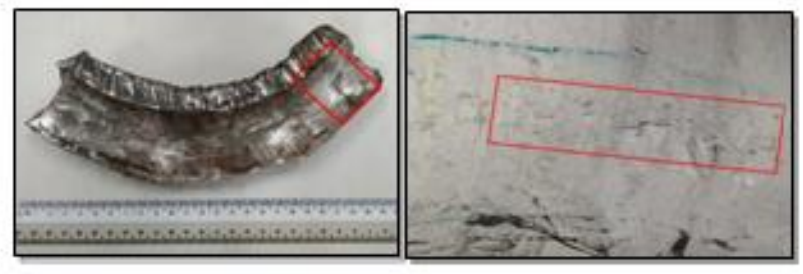

Fig 2. Crack finding in curvature area

\section{B. Heat Treatment}

Heat treatment is a process of altering the structure of the

Retrieval Number: B2512129219/2020@BEIESP

DOI: 10.35940/ijeat.B2512.049420

Journal Website: www.ijeat.org material in order to achieve desired properties [10]. Previous research showed that post-weld heat treatment was the method that could reduce the stress in steel that was generated from the welding process [14-15]. The process of post-weld heat treatment consisted of a sequence of controlled heating and cooling steps applied to the welded structure using externally applied heating elements. This process gave the metal time to readjust to its original, prefabrication state and removed residual stress. The carbon in the steel became less reactive, inhibiting the reaction with hydrogen to form methane. Chemical resistance to HTHA was thus modestly improved in post-weld heat-treated steels.

The failed part was annealed to $850^{\circ} \mathrm{C}\left(1562^{\circ} \mathrm{F}\right)$ with the heating rate of $20^{\circ} \mathrm{C}$ per minute. The holding time was set for 2 hours. The thickness of the specimen was about $2.54 \mathrm{~cm}$ (1-inch). Complete austenite would normally take at least 60 minutes with the holding time of 2 hours. Then, the specimen was slow cooled in a furnace. It took about 20 hours for the furnace to cool down to room temperature. The slow cooling rate was needed to avoid unwanted cracking on the specimen that would affect the aims of this research.

\section{RESULTS AND IDSCUSSIONS}

Carbon steel is more susceptible to HTHA compared to all other materials of construction. HTHA damage mechanism occurs when carbon steel equipment is exposed to hydrogen at high temperatures and high hydrogen partial pressures. HTHA focuses on the high-stress area in carbon steel like a post-weld-heat-treated area and bending areas in the form of fissures. Predicting and identifying equipment damage due to HTHA is complex. The MPI technique was able to clearly reveal the crack that penetrated which was initiated by decarburization. 5 samples identified as fissuring and cracks due to HTHA at weldment areas were selected and included at the heat affected zone (HAZ).

\section{A. Visual Inspection}

Fissures formed are due to very high pressure exerted by methane gas inside the equipment. As more fissures are formed, it leads to the formation of microcracks. Furthermore, these microcracks can also combine with other microcracks to form larger cracks that greatly weaken the steel and leads to the rupture of the equipment.

Visual identified cracks presence on circumference (concave surface) inner surface of the carbon steel caused by the hydrogen attack. Fig 1(a) showed the carbon steel pipe that already undergoes failure due to hydrogen attack which has been cut by oxy-acetylene torch cutting and wire-cut EDM cutting on the welding area (high-stress area).

\section{B. Post Heat Treatment Characterisation}

Heat treatment was done on the specimen to observe the reduction of crack length after undergoing heat treatment. It was annealed to $850^{\circ} \mathrm{C}$ with a holding time of two hours. The crack length of the specimen is reduced to $9 \mathrm{~mm}$ from $13 \mathrm{~mm}$ after undergoing heat treatment with a total crack reduction of $30.77 \%$ as shown in Fig 3 while Table 2 listed the crack reduction. Visual inspection also identified of oxide layer during heat treatment was fragile and can easily scrapped off.

Published By:

Blue Eyes Intelligence Engineering \& Sciences Publication

(C) Copyright: All rights reserved.

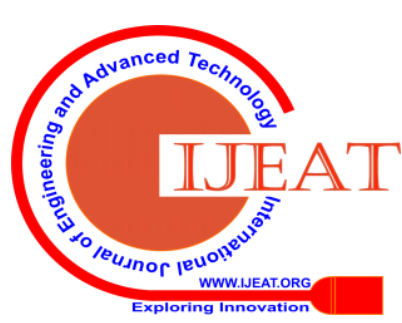




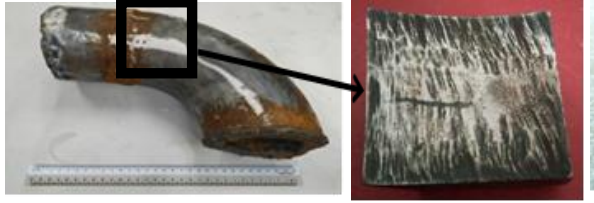

(a)

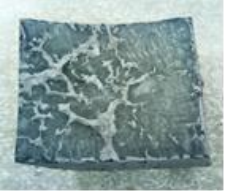

(b)
Fig 3: Crack on the surface of carbon steel (a) before and (b) after heat treatment

Table 2. Heat treatment results

\begin{tabular}{|c|c|c|c|}
\hline \multirow{2}{*}{ Sample } & \multicolumn{2}{|c|}{ Length of crack (mm) } & \multirow{2}{*}{ \% reduction } \\
\cline { 2 - 4 } & Before & After & \\
\hline 1 & 20.15 & 18.05 & 10 \\
\hline 2 & 3.30 & 3.15 & 4.5 \\
\hline 3 & 8.20 & 7.80 & 4.9 \\
\hline 4 & 15.15 & 14.65 & 3.3 \\
\hline 5 & 11.05 & 10.65 & 3.6 \\
\hline
\end{tabular}

The crack length was measured using Vernier caliper. Sample 1 shows the most crack reduction due to heat treatment compared to other specimens. However, the hardness of the sample in this research had reduced after the heat treatment process. This reveals that the mechanical properties of the pipeline did not improve after the heat treatment. However, there was a chance of an HTHA crack reduction when the sample underwent heat treatment.

There were possibilities that the carbon had diffused into the matrix and the hydrogen atoms had escaped and had a tendency to return to a lower Gibbs free energy condition before the cracks appeared [16-18]. Diffusion played an important part in the healing of HTHA crack as it was the key role in the HTHA process [19-21]. Despite the reduction of crack length, further investigation is needed to improve the failed part to how it used to be.

\section{Microstructure Analysis}

By observing the crack under the optical microscope, the images of the crack were obtained. The crack on the carbon steel specimen was caused by the formation of methane gas $\left(\mathrm{CH}_{4}\right)$, results from reaction of hydrogen with carbon in the steel. As the temperature and pressure were high, the methane gas did not escape and causing cracks on the wall of the carbon steel pipe (High Temperature Hydrogen Attack). Hence, Fig 4 below showed the crack that was contributed by the methane gas. The crack image that was observed under an optical microscope is $10 \mathrm{x}$ magnification.
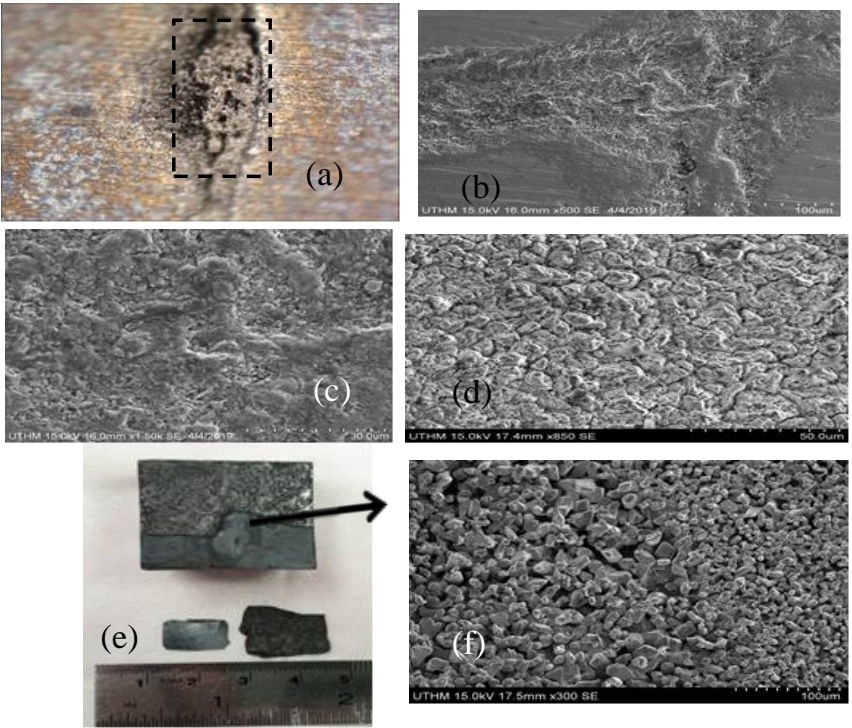

Fig 4: Crack on carbon steel at different magnification and oxide layers (right bottom).

SEM result on the metallography was done before the specimen which is the carbon steel undergo heat treatment and also after undergoing heat treatment. Fig 4 (e) and (f) show the crack surface image observed by SEM showing intergranular cracks of corrosion. Moreover, decarburization occurs where carbon steel loses the amount of carbon. It can be seen in Fig 4(b). The difference between the crack area and the not affected area showed that decarburization has occurred to the carbon steel that has been subjected to HTHA. The microstructure also was identified after the heat treatment. It was revealed that the surface was fully covered by oxide layer after the heat treatment. Fig 4 (e) and (f) how the base metal after heat treatment without oxide layer attached. The surface denser with porous granulations showing some carbon missing during hydrogen attack. The white granules seem to appear in numbers on the surface without an oxide layer. The oxide layer easily peeled off showing that a fragile and crystalline like structure (Fig. 4 (f)) was formed during heat treatment.

\section{Electrochemical}

The electrochemical was run for Tafel scan to identified current density after the sample had gone through heat treatment. The scan rate used is $2 \mathrm{mV} / \mathrm{sec}$ where the area of the specimen is $8 \mathrm{~cm}^{2}$. The value of corrosion current density $\left(I_{\text {corr }}\right)$, corrosion potential $\left(E_{\text {corr }}\right)$, open circuit potential $(O C P)$ and corrosion rate (CR) can be obtained. Tafel plot as shown in Fig 3 gives the values $17.974 \mu \mathrm{A},-656.783 \mathrm{mV}$ and -656.9 $\mathrm{mV}$ for $I_{\text {corr }}, E_{\text {corr }}$, OCP respectively.

The corrosion rate was then calculated and given to value $26.081 \mathrm{~mm} /$ year. Quite a high rate due to oxidation reaction to give oxide layer for protection purposes. This gives a sign that the corrosion rate characterised the value of oxidation rate to formed oxide layer on carbon steel.

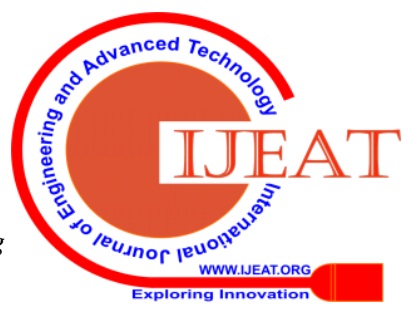




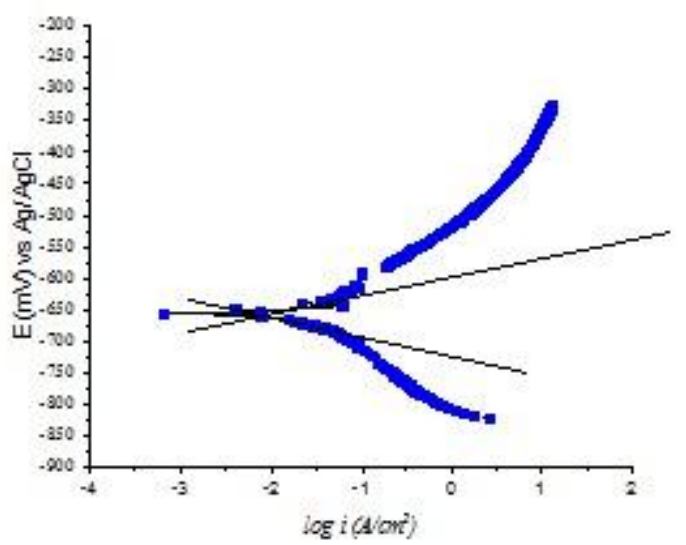

Fig. 5: Electrochemical by Tafel scan to identify current density and other corrosion properties

\section{E. Hardness}

Based on the result obtained for the hardness test before and after undergo heat treatment, it showed an increasing value for the hardness. An average is taken as the hardness value for before and after undergo heat treatment. Hardness before heat treatment was $115.18 \pm 0.14$ and after the carbon steel undergoes heat treatment, the value of hardness is increasing to $122.9 \pm 0.00$. It can be concluded that by doing heat treatment, the hardness of the carbon steel can be increased. Fig 14 shows the hardness graph. In the beginning, carbon steel was heated to a high temperature to convert the entire structure to the austenite phase. After that, upon slow cooling of austenite, austenite would change to coarse pearlite that is formed with a thick ferrite and cementite layers. For instance, upon cooling, austenite having a half carbon concentration and transform to a ferrite phase which is much lower carbon content and cementite phase which is much higher carbon content. Pearlite is the microstructural product of the transformation which is fairly tough. The slower the cooling rate, the thicker the pearlite layers are [5]. Hence, it influences the hardness result on why the result of hardness increase after undergoes heat treatment. It is due to the toughness characteristic of the pearlite. Hardness for pearlite is for about 180 B.H.N [6].

\section{CONCLUSION}

HTHA is a damage mechanism that results in fissures and cracking which occurs when carbon steel equipment is exposed to hydrogen at high temperatures and pressures. The samples were taken from a cut-off pipeline which had failed during an operation due to HTHA. Failure analysis by MPI successfully revealed the locations of HTHA at weldment areas. The failure still occurred even though the pipeline was operated at a below design temperature, which was considered safe. By applying heat treatment to annealing temperature of $850^{\circ} \mathrm{C}$ and slow cooled in the furnace the crack length was reduced to $3 \%-10 \%$. This shows that heat treatment can be an alternative choice before further action can be made. Certainly, upgrading the equipment material of construction to a more HTHA-resistant steel is the best choice to promote safer choice in material selection.

\section{ACKNOWLEDGMENT}

The authors would like to thank the Ministry of Higher Education Malaysia and Research Management Center of Universiti Tun Hussein Onn Malaysia for funding this research by Tier U873 and Vot E15501.

\section{REFERENCES}

1. I. Azzura, M.S.N. Farhana, M.N. Lokman, "Identification corrosion hydrogen attack on carbon steel using magnetic particle inspection (MPI)," Int. Conf. on Mech. Eng. Research and Application, 2nd ed. vol. 3, J. Peters, Ed. New York: McGraw-Hill, 494, 2019, pp. 1-8.

2. H. Fujikawa and S. B. Newcomb, Oxidation of Metals, Vol.77, 2012,pp.85.

3. M. B. Djukic, V. Sijacki Zeravcic, G. M. Bakic, A. Sedmak, and B. Rajicic, "Hydrogen damage of steels: A case study and hydrogen embrittlement model,” Eng. Fail. Anal., vol. 58, pp. 485-498, 2015.

4. API, "Damage Mechanisms Affecting fixed Equipment in the Refining Industry RP 571," Am. Pet. Inst., no. April 2011, p. 372, 2011.E. H. Miller, "A note on reflector arrays (Periodical style-Accepted for publication)," IEEE Trans. Antennas Propagate., to be published.

5. Baker Engineering And Risk Consultants, Inc. Locations San Antonio Houston | Los Angeles | Chicago Toronto, Canada | Chester, United Kingdom

6. H. C. Qua et al., Applied Engineering Failure Analysis: Theory and Practice. CRC Press, 2015.

7. J. L. Otegui, Failure Analysis: Fundamentals and Applications in Mechanical Components. 2014.

8. P. A. Schweitzer, C. P. Systems, and P. A. Schweitzer, Corrosion Mechanisms in Theory and Practice. 2011.

9. D. Loder, S. K. Michelic, and C. Bernhard, "Acicular Ferrite Formation and Its Influencing Factors-A Review,” J. Mater. Sci. Res., vol. 6, no. 1, p. 24, 2016.

10. A. M. El-Melih, A. Al Shoaibi, and A. K. Gupta, "Reformation of hydrogen sulfide to hydrogen in the presence of xylene," Appl. Energy, vol. 203, pp. 403-411, 2017.

11. H. K. D. H. Bhadeshia, "Prevention of Hydrogen Embrittlement in Steels," ISIJ Int., vol. 56, no. 1, pp. 24-36, 2016.

12. T. J. Carter and L. A. Cornish, "Hydrogen in Metals," Phys. Metall. Fifth Ed., vol. 1, no. 2001, pp. 2597-2705, 2001.

13. N. H. Heo, Y. C. Jung, J. K. Lee, and K. T. Kim, "Decarburization, grain boundary segregation of $\mathrm{P}$ and primary water stress corrosion cracking in a low-alloy steel," Scr. Mater., vol. 59, no. 11, pp. 1200-1203, 2008.

14. P. W. Eva Mazancova, Zdenek Jonsta, "Acicular Ferrite and Bainite Microstructure Properties and Comparison of Their Physical Metallurgy Response," Metal, vol. 5, p. 7, 2005.

15. C.F Dong, X.G. Li, z.S. Shen, W.Y. Chu, "Study on Crack Healing of Hydrogen Attack in Carbon Steel by Heat Treatment', Corrosion, vol 59 (5), p.401-406.

\section{AUTHORS PROFILE}

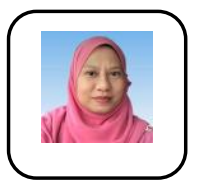

Dr Azzura Ismail is currently a lecturer at Universiti Tun Hussein Onn Malaysia with more than 16years experience in teaching. She has a strong background teaching in materials engineering and research in corrosion. She was awarded as a doctor of philosophy from University of Leeds, UK and was published several papers in corrosion related area. She currently an active membership of NACE International and holds a position treasurer of NACE Founding Malaysia Section since 2014. She also an active member of Institute of Materials Malaysia (IMM) and Malaysia Tribology (Mytribos). She also registered as Board of Engineers Malaysia (BEM) and was awarded excellent 10 years' service for UTHM in 2013.

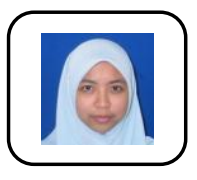

Asliaty Atim is a lecturer at Universiti Tun Hussein Onn Malaysia (UTHM). She was graduated from the University of Stockton in Bachelor of English and Master degree in education TESL from University Technology Malaysia (UTM).

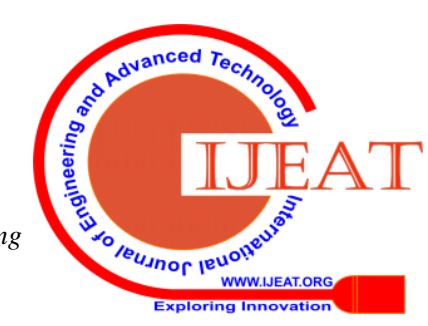


Azlizul Aizat Razali graduated from the Universiti Tun Hussein Onn Malaysia (UTHM) in Mechanical Engineering. He currently pursues his $\mathrm{PhD}$ program with the topic of detecting corrosion by CFD. He is an active member of Institute of Materials Malaysia (IMM).

Muhammad Amin Ali graduated in Mechanical Engineering (Hons) from the Universiti Tun Hussein Onn Malaysia (UTHM). He currently pursues his postgraduate study in Master of Technical and Vocational Education. $\mathrm{He}$ is an active member of National Association of Corrosion Engineers (NACE) International.

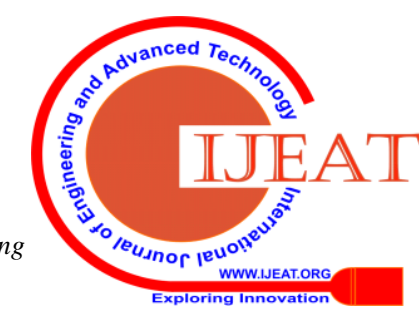

